major surgical centres and most had a trained nurse, visiting doctor, and psychotherapist. Employment of the child after school was often difficult.

\section{Integration into Family and Community}

Mr. R. B. Zachary (Sheffield) discussed the integration of the child into the family and commnity. Spina bifida was a serious disappointment to the parents, he said, and it was essential to establish a close tie between the family and child from an early stage. Sometimes the parents were afraid to handle the child and they should be encouraged to do so while the child was still in hospital. It was essential to see that parents were not visiting too many different hospitals, and joint follow-up clinics were of importance in preventing this. Societies were valuable in telling parents about the facilities available to them. The specialist was under an obligation to keep the general practitioner well informed of modern treatment, as frequently the parents would be extremely well informed. Mr. Zachary paid tribute to the work being done by various societies in supporting the morale of parents and in telling the public that handicapped children could contribute to the community but that they might need special help in doing so.

NEW APPLIANCES

\title{
Device for Control of Incontinence of Urine in Women
}

Mr. L. E. EDWARDs, $†$ surgical registrar, University College Hospital, London, W.C.1, writes: A new mechanical device has effectively reduced the degree of incontinence of urine in 17 out of 19 consecutive patients studied.

The Device.-A fenestrated plastic triangle fits over the mons pubis. From this triangle a stainless steel wire, $12 \mathrm{~cm}$. long and covered with polyethylene, follows the curve of the vulva to bend at a right-angle and terminate in a curved, corrugated plastic pad (Figs. 1 and 2). This pad exerts gentle pressure on the urethra through the anterior

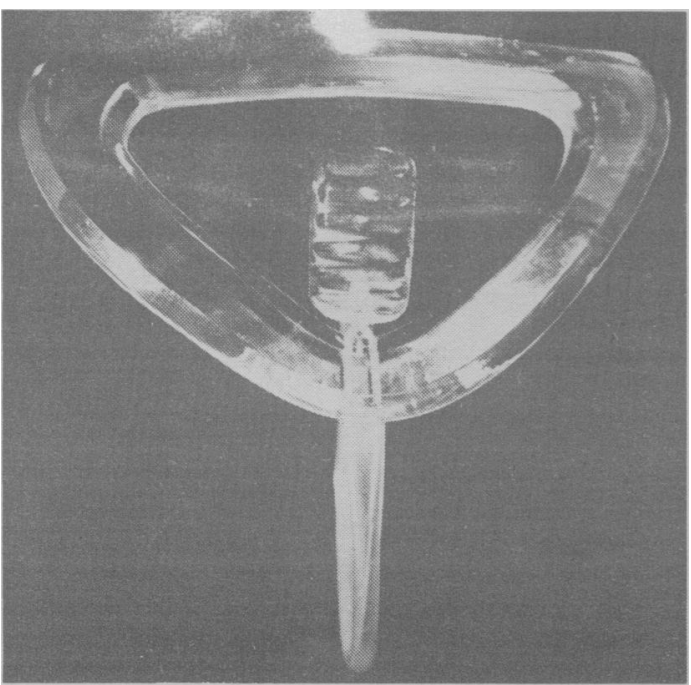

Fig. 1. - Front view of device

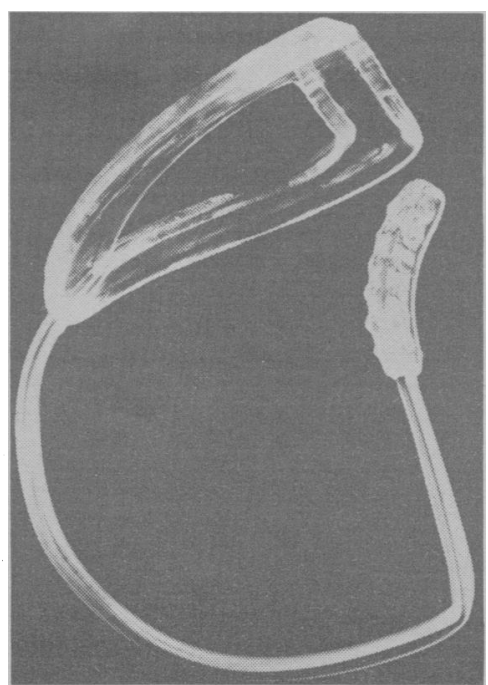

Fig. 2. - Side view of device has said that after a day or two it is not noticeable when in use. Frequent examination of the patients has shown one case of vaginal trauma. The types of patient who used this device are shown in Table $I$, and the results of the study are given in Table II. Patients with grade $\mathbf{A}$ incontinence at night did not wear the device at night. Two patients $(B \rightarrow A / A)$ and $(D \rightarrow A / D \rightarrow A)$, abandoned the device because they did not like wearing it. None of the patients with group 3 incontinence, two $(C \rightarrow A / C \rightarrow A)$ patients, and one $(E \rightarrow A / E \rightarrow A)$ patient, was able to tolerate the device, nor was a 78 year-old woman $(\mathrm{E} \rightarrow$ ? $/ \mathrm{E} \rightarrow$ ?) with group 2 incontinence. The arrow indicates conversion from one grade to another on using the device.

Full details of the results and of the materials used in the trial will be published later. The results have been encouraging, especially in view of the facts that all the patients considered were : (1) those in whom surgical procedures had failed, (2) those in whom surgical procedures were contraindicated for medical reasons, and (3) those for whom no other form of control was available.

I would like to thank Mr. D. R. Davies, of University College Hospital, and Professor J. P. Blandy, of St. Peter's Hospital and the London Hospital, for their encouragement and advice. Miss Eileen Brown, of the department of PhotoMiss Eileen Brown, of the department of Photography, Barnet Gens
took the photographs.

The device is manufactured by Kinpax Surgical Ltd. of Southend, and distributed by Messrs. Thackray of Leeds.
TABLE I.-Type of Incontinence and Number of Operations

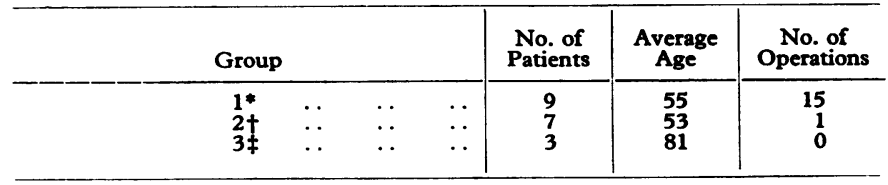

*Stress incontinence. †Neurogenic incontinence. $¥$ “Geriatric" incontinence.
TABLE II_-Grades of Incontinence Before and After Use of Device

\begin{tabular}{|c|c|c|c|c|c|}
\hline & Grade & Before & Use & & \\
\hline $\mathbf{A}$ & B & C & D & $\mathbf{E}$ & Use \\
\hline $0 / 8^{*}$ & $3 / 0$ & $\begin{array}{l}4 / 1 \\
1 / 1\end{array}$ & $\begin{array}{l}4 / 4 \\
3 / 1 \\
1 / 0 \\
0 / 1\end{array}$ & $\begin{array}{l}2 / 2 \\
1 / 1\end{array}$ & $\begin{array}{l}\mathbf{A} \\
\mathbf{B} \\
\mathbf{C} \\
\mathbf{D} \\
\mathbf{E}\end{array}$ \\
\hline
\end{tabular}

$A=$ Continent. $B=$ Damp. $C=$ Wet. $D=$ Soaking. $\mathbf{E}=$ Catheter. day, and those on Right the Number of Patients in Grade during night. 